\title{
Preoperative Elevated International Normalized Ratio Cannot Increase Transfusion or Complication in Primary Total Hip Arthroplasty: A Retrospective Study of 552 Cases
}

\author{
Linbo Peng \\ Sichuan University West China Hospital \\ Junfeng Zeng \\ Sichuan University West China Hospital \\ Yi Zeng \\ Sichuan University West China Hospital \\ Yuangang Wu \\ Sichuan University West China Hospital \\ Jing Yang \\ Sichuan University West China Hospital \\ Bin Shen ( $\nabla$ shenbin_1971@163.com ) \\ West China Hospital, Sichuan University https://orcid.org/0000-0002-9632-7221
}

\section{Research article}

Keywords: Total Hip Arthroplasty (THA), International Normalized Ratio (INR), Tranexamic Acid (TXA), deep venous thrombosis (DVT), muscular vein thrombosis, subcutaneous ecchymosis

Posted Date: June 8th, 2020

DOI: https://doi.org/10.21203/rs.3.rs-31106/v1

License: (c) (1) This work is licensed under a Creative Commons Attribution 4.0 International License. Read Full License 


\section{Abstract}

Background: Verify if the elevated preoperative International Normalized Ratio (INR) can increase transfusion and complication rate in primary total hip arthroplasty.

Methods: We retrospectively reviewed the database of adults who underwent primary total hip arthroplasty between 2014 to 2018 by the same surgeon. 552 cases were assigned into 3 groups by preoperative INR class: INR $\leq 0.9,0.9 \otimes I N R \otimes 1.0$, and INR $\geq 1.0$ eventually. We regarded the transfusion rate as the primary outcome. We also included perioperative blood loss, maximum $\mathrm{Hb}$-drop, postoperative anemia needs medicine, length of stay (LOS), re-operation, the complication rate in 90 days and mortality as the secondary outcomes. Univariable analyses were utilized to compare baselines and outcomes between groups. Binary Logistic Regression was used to adjust differences of baselines among groups.

Results: All the cases had an INR $₫ 1.5$. Among all the cases, 93(16.8\%) had INR $\leq 0.9,268$ (48.6\%) had 0.9凶 INR 1.0 , and 191 (34.6\%) had INR $\geq 1.0$, respectively. In the univariable analyses, with the INR elevated, The transfusion rates increased from $1.08 \%$ for INR $\leq 0.9,1.12 \%$ for 0.9 INRR 1.0 to $5.76 \%$ for INR $\geq 1.0$ ( $p \rrbracket$ 0.05). The overall complication rate increased from $10.8 \%$ for INR $\leq 0.9,16.4 \%$ for 0.9 \INR 1.0 to $22.5 \%$ for INR $\geq 1.0$ ( $p \otimes 0.05$ ). When controlling for the demographics and comorbidities characteristics, there was no statistically significant difference when evaluating the odds of transfusion nor overall complication rate between the groups $(\mathrm{p} \otimes 0.05)$.

Conclusions: The transfusion and complication rate cannot increase along with the INR elevated in primary THA. With the improvement of arthroplasty protocol and use of tranexamic acid, the INR 1.5 was still a conventional safe threshold.

\section{Background}

Total hip arthroplasty (THA) is considered one of the most successful surgeries in the history of modern medicine[1]. With the aging population and the prevalence of obesity[2], the utilization and cost of THA have grown annually[3]. THA is associated with excessive perioperative blood loss and a high need for transfusion[4, 5], as well as THA related complications. Of all the reasons for THA revision, dislocation and mechanical loosening are the main indications [6].

INR refers to the ratio of prothrombin time to the normal prothrombin time[7] $₫$ which were regarded as an ideal method for judging the anticoagulation effect[8]. It can overcome variability between different laboratories by thromboplastin sensitivity[9]. Among the warfarin used patients, INR was kept between 2.0 and 3.0 as the therapeutic range[10]. A preoperative international normalized ratio (INR) target $<1.5$ is suggested by the guidelines[11]. INR was widely used in predicting mortality and bleeding in some diseases. Rudasill et al found that INR showed an important value in predicting mortality and bleeding in End-Stage Liver Disease[11]. Tan et al observed that patients who underwent endarterectomy with high preoperative INR ( $\geq 1.5)$ exhibited higher 90-day mortality than ones with low INR[12]. In another study 
about manage heart failure with nonvalvular atrial fibrillation, abnormal INR also showed higher independent risks of mortality[13].

Some previous studies agreed that high INR values have a strong association with the risk of bleeding[14, 15]. A retrospective study found patients with INR $\geq 1.3$ had a higher transfusion rate in victims of abusive head trauma[16]. An elevated INR is also associated with increased complications after hand surgery[17].

Recently, a retrospective study of more than twenty thousand cases proved INR囚1.25 was tightly associated with bleeding, infection, and mortality in total knee arthroplasty[18]. The same author conducted another similar retrospective study in THA and found elevated INR increased bleeding and mortality again[19]. But the evidence for INR to predict perioperative bleeding, complication and mortality are still low.

Previous research mainly focuses on the comparison of high INR such as $₫ 1.25$, even $₫ 1.5$.

The predictive value of INR in conventional safe thresholdX1.5 is still uncertain. The relationship between INR and some THA-related complications such as dislocation, fracture and vein thrombosis needs intensive studying too. The purpose of this retrospective study was to verify if the elevated preoperative INR can increase transfusion and complication in primary total hip arthroplasty when INR was in conventional safe threshold $\Downarrow 1.5$.

\section{Methods}

We retrospectively identified a database of adults who underwent total hip arthroplasty between October 15,2014 , to October 14,2018 , by the same senior surgeon(B.S). We obtained relevant in-hospital data by checked medical records in our hospital system. We contacted the discharged patients to get their complication, re-operation, and mortality information after discharge. We brought adult cases ( $\geq 18$ years of age) who underwent primary total hip arthroplasty into our study. We only included cases with enough relevant pre-operative laboratory data including INR, which was collected within three days preoperatively. Exclusion criteria included bilateral THA during the same hospitalization, THA after acute infection, revision operation, multiple fractures and patients without adequate data.

All the cases were divided into 3 groups by preoperative INR class: INR $\leq 0.9,0.9 \unrhd \operatorname{INR} \rrbracket 1.0$, and INR $\geq 1.0$. We regarded postoperative transfusion rate during the same hospitalization as the primary outcome. We also included perioperative blood loss, maximum $\mathrm{Hb}$-drop, postoperative anemia needs medicine, length of stay (LOS), re-operation, the complication in 90 days, mortality in 90 days and mortality in 12 months as the secondary outcomes. Postoperative complications contained urinary tract infection, renal failure, stroke, cardiovascular accident, pneumonia, stroke, septic shock, pulmonary embolism (PE), deep venous thrombosis (DVT), superficial infection, deep infection, dislocation, fracture, muscular vein thrombosis, subcutaneous ecchymosis, hematoma and wound-healing delay, etc. Perioperative blood loss was calculated by the formulas described by Gross with preoperative hematocrit and the lowest postoperative 
hematocrit during hospitalization[20-22]. All the complications, re-operation and complication data in the first 90 days postoperatively were collected. Mortality in 12 months was brought into the study.

We compared the demographics and comorbidities characteristics of cases by the INR group. Continuous variables were exhibited as the mean with the standard deviation or as the median with the interquartile range. Categorical variables were exhibited as the number of cases (the percentage). We analyzed continuous variables by one-way ANOVA with post-hoc Tukey test, and categorical variables by the chisquare test or Fisher test. We utilized Binary Logistic Regressions to evaluate the predictive value of INR for transfusion and complication. We put the independent variables of $p<0.1$ into the regression model for adjustment. Regressions were adjusted for contralateral THA, ASA class, asymptomatic bacteriuria, cardiac pacemaker, pre-operative hemoglobin, hematocrit, WBC count and serum albumin eventually. In all the comparisons, $p<0.05$ was considered statistically significant. We performed all the statistical analyses by SPSS (version 26; IBM).

\section{Results}

\section{Demographic and comorbidities characteristics}

From October 15, 2014, to October 14, 2018, 589 cases were screened for eligibility. 21 cases were excluded: 14 failed to meet the inclusion criteria, 7 were lack of adequate preoperative data. We allocated remaining cases into three groups by the class of INR. 3, 8, 5 cases lost follow-up information in the three groups respectively. There was no significant difference in the distribution of lost-to-follow-up cases among groups. 552 cases were included in our study finally (Fig. 1).

All the cases had an INR $₫ 1.5$, which was considered as a conventional safe threshold. Among all the

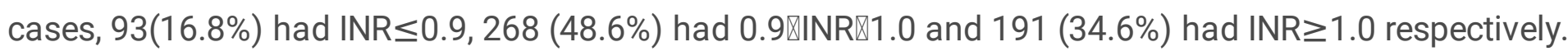
With the INR elevated among groups, The American Society of Anesthesiologists(ASA) class increased gradually ( $\mathrm{p} \otimes 0.05)$. The proportion of contralateral THA was different among groups, which was (29.0\%)

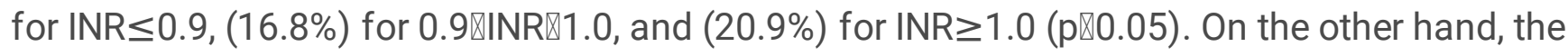
preoperative hematocrit decreased from $0.415 \pm 0.037 \mathrm{~L} / \mathrm{L}$ for INR $\leq 0.9,0.406 \pm 0.041 \mathrm{~L} / \mathrm{L}$ for $0.9 \rrbracket \mid N R \rrbracket 1.0$ to $0.398 \pm 0.045 \mathrm{~L} / \mathrm{L}$ for $I N R \geq 1.0$ ( $\mathrm{p} \otimes 0.05$ ). Serum albumin also decreased from $44.8 \pm 4.7 \mathrm{~g} / \mathrm{L}$ for INR $\leq 0.9$, $43.8 \pm 4.1 \mathrm{~g} / \mathrm{L}$ for $0.9 \otimes I N R \rrbracket 1.0$, to $42.9 \pm 4.5 \mathrm{~g} / \mathrm{L}$ for $I N R \geq 1.0$ ( $\mathrm{p} \otimes 0.05$ ). The cases with cardiac pacemakers were different among groups as $0.0 \%$ for INR $\leq 0.9,0.0 \%$ for $0.9 \otimes I N R \otimes 1.0$, and $2.1 \%$ for INR $\geq 1.0$ (pष0.05). There were no statistical differences between INR groups in ages, genders, BMI, Comorbidities except cardiac pacemaker, pre-operative ESR, Platelet count, WBC count, or D-Dimer (Table 1).

\section{Clinical outcomes}

As presented in Table 2, With the INR elevated, The transfusion rates increased from 1.12\% for 0.9 INR 1.0 to $5.76 \%$ for INR $\geq 1.0(p=0.004)$. There was no statistically significant difference about the transfusion rate in Group A vs. Group B or Group A vs. Group C ( $p=1.000, p=0.112$, respectively). The

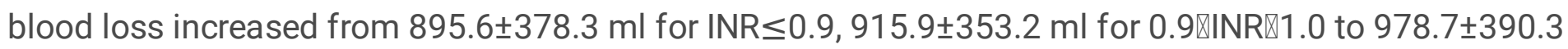


$\mathrm{ml}$ for INR $\geq 1.0$ in mean, but there were no statistical differences detected $(p=0.892, p=0.180, p=0.174$, respectively). The maximum $\mathrm{Hb}$ drop increased from $25.7 \pm 10.5 \mathrm{~g} / \mathrm{L}$ for INR $\leq 0.9,26.3 \pm 9.9 \mathrm{~g} / \mathrm{L}$ for 0.9 IINR $\nabla 1.0$ to $27.3 \pm 9.9 \mathrm{~g} / \mathrm{L}$ for INR $\geq 1.0$ in mean, which were not statistically different among the three groups $(p=0.857, p=0.406, p=0.553$, respectively). The incidence of anemia needs medication also increased gradually among groups with no statistical significance. Length of stay (LOS) in group C was $5.7 \pm 2.2$ days, which was statistically longer than ones in group $A(4.7 \pm 1.6$ days, $p=0.000)$ and group $B(5.1 \pm 2.0$ days, $p=0.007$ ) (Fig.2).

Among all the cases, 10 (10.8\%) in Group A, 44 (16.4\%) in Group B and 43 (22.5\%) in Group C had complications reported postoperatively. There was a statistical difference in complications between Group A and Group $\mathrm{C}(\mathrm{p}=0.017)$. Continuous increasing trends were observed among groups about the incidence of cardiovascular accident, superficial infection, muscular vein thrombosis, subcutaneous ecchymosis, wound-healing delay and re-operation without statistical significance. We also found no statistical differences among groups about urinary tract infection, renal failure, stroke, pneumonia, stroke, septic shock, pulmonary embolism, DVT, deep infection, dislocation, fracture, hematoma, wound-healing delay, mortality in 90 days and mortality in 12 months (p凶0.05) (Table 3).

After adjusted for independent variables of $p<0.1$ into the regression model, we found no statistical difference in transfusion (Table 4) and complication at 90 days (Table 5) among the three groups. We adjusted for contralateral THA, ASA class, asymptomatic bacteriuria, cardiac pacemaker, pre-operative hemoglobin, hematocrit, WBC count and serum albumin.

\section{Discussion}

Preoperative elevated INR had been confirmed to increase bleeding, complication and mortality in some diseases[11-17]. Measuring INR before joint surgery was a standard pattern in our institution. But few studies explored the relationship between elevated INR and postoperative outcomes in total joint replacement, which was related to the risk of transfusion closely. In this retrospective study of 552 cases, we found the transfusion and complication rate cannot increase along with the INR elevated in primary THA.

In the group of INR $\geq 1.0$, more cases had ASA class 3 and 4 with statistical significance $(p=0.005)$, which was relatively high risk. Knol et al also found the proportion of high ASA class in the patients with INR $\geq 1.8$ was higher than ones with INR $₫ 0.8(69 \%$ and $48.7 \%$, respectively, $p=0.036)[23$ ]. A larger proportion of cases $(29.0 \%)$ in the INR $\leq 0.9$ group had contralateral THA than other groups with statistical significance. Some other studies showed contralateral surgery increases the risk of recurring complications in both THA and TKA[24, 25]. We did not find this trend in our study. Demographic data showed cases in high INR values had statistically lower preoperative hematocrit and serum albumin, Rudasill et al detected similar baseline data in THA and TKA[18, 19]. There were no statistical differences in other demographic and comorbidities characteristics among groups. 
This is the first study, as far as we know, found the transfusion and complication rate cannot increase along with the INR elevated in primary THA. Our findings were different from a recent study of Rudasill SE [19], who retrospectively analyzed 17,567 patients by the National Surgical Quality Improvement Program (NAQIP). His team and he found increased bleeding risk with INR 1.25 to $\mathbb{Q} 1.5(\mathrm{OR}, 1.55[95 \% \mathrm{Cl} 1.26$ to 1.92]) and increased risk of mortality with INR $\geq 1.5 \otimes O R, 2.69$ [95\% $\mathrm{Cl}, 1.07$ to 6.76$]$ ] 1.0. There are several reasons account for these differences. First, Rudasill SE[19] focused their study on the patients between 2005 to 2016, while we included the latest cases between 2014 and 2018 only. With the improvement of arthroplasty protocol and use of tranexamic acid, our institute has greatly reduced transfusion, complication, and mortality in total joint arthroplasty[26-29]. Since 2012, almost all the patients who underwent TKA or THA surgery in our institution have received tranexamic acid during the perioperative period. In our institution, ESR and CRP must be controlled in not more than two times the normal range before the operation for most patients, and not more than three times for inflammatory disease patients such as rheumatoid arthritis and SLE. Asymptomatic bacteriuria must be cured before arthroplasty surgery. Thus, our average transfusion rate of all cases was $2.7 \%$, which was largely lower than Rudasill SE (15.5\%). The mortality in 90 days of Rudasill SE's study is $0.8 \%$, while we have no patient died in three months after surgery. A ten-year national database from the UK also showed postoperative complications reduced year by year in THA, although the levels of comorbidity elevating[30]. Second, some THA-related complications such as dislocation, fracture, wound-healing delay, and vein thrombosis were not included by Rudasill SE. Also, we followed up the mortality rate in 12 months and found no statistical difference among the groups. The debate about INR security thresholds has been going on for a long time. Some previous studies agreed that high INR values have a strong association with the risk of bleeding in heart valve replacement and head trauma[14-16]. But some others observed that an elevated INR did not increase bleeding risk in chest tube placement and hand surgery[31, 32].

With the INR elevated by the class step, the length of hospital stay increased gradually compared with INR $\leq 0.9$ with statistical significance. Similar results can be found in other studies[18, 19, 33]. We included some minor complications in our study such as muscular vein thrombosis and subcutaneous ecchymosis, which were common in other studies[34-38]. In the aspect of specific complications, an increasing trend can be detected about the incidence of cardiovascular accident, superficial infection, muscular vein thrombosis, subcutaneous ecchymosis, and wound-healing delay. But there was no statistical difference in this growing trend. We detected no statistical difference in re-operation, mortality in 90 days or mortality in 12 months.

There are some limitations to the current study. First, because this was a retrospective study, there may be some nature bias about the data. Second, sixteen cases lost follow-up among them all, but there was no significant difference in the distribution of lost-to-follow-up cases among groups (3.1\%, $2.9 \%, 2.6 \%$, respectively). Thus we believed our lost-follow-up rate was acceptable for these parameters. Third, some patients failed to report adequate information because of forgetting, which may lower the complication rate. But we get most postoperative outcomes data during hospitalization. Other postoperative outcomes were mainly included major complications, re-operation, and mortality, which were unlikely to be forgotten 
by patients and their families. Therefore, we did not think those limitations would affect the results severely.

\section{Conclusions}

In conclusion, the transfusion and complication rate cannot increase along with the INR elevated in primary THA. With the improvement of arthroplasty protocol and use of tranexamic acid, the INR囚1.5 was still a conventional safe threshold for THA surgery

\section{Abbreviations}

INR, International Normalized Ratio; LOS, Length of Stay; THA, Total Hip Arthroplasty; TXA, Tranexamic Acid; PE, Pulmonary Embolism; DVT, Deep Venous Thrombosis; ESR, Erythrocyte Sedimentation Rate; CRP, C-reactive protein; TKA, Total Knee Arthroplasty; BMI, Body Mass Index; ASA, American Society of Anesthesiologists; COPD, Chronic Obstructive Pulmonary Diseases; SLE, Systemic Lupus Erythematosus; AS, Ankylosing Spondylitis; WBC, White Blood Cell.

\section{Declarations}

\section{Ethics approval and consent to participate}

The study was approved by the Ethical Committee of West China Hospital of Sichuan University. And the written informed consent was obtained from each patients included in the study.

\section{Consent for publication}

Not applicable.

\section{Availability of data and material}

All data and materials are contained within the manuscript.

\section{Competing interests}

The authors Linbo Peng, Junfeng Zeng, Yi Zeng, Yuangang Wu, Jing Yang, and Bin Shen declare that they have no conflicts of interest.

\section{Funding}

This study was not supported by any funding sources.

\section{Authors' contributions}


The following authors designed the study (BS), collected the data (LBP,JFZ), analysed the data (LBP, YGW), wrote the initial drafts (LBP), and ensured the accuracy of the data and analysis (BS, JY, YZ). All authors read and approved the manuscript.

\section{Acknowledgements}

All authors have approved this study for publication.

\section{References}

1. Perets I, Mu BH, Mont MA, Rivkin G, Kandel L, Domb BG. Current topics in robotic-assisted total hip arthroplasty: a review. Hip Int: 1120700019893636, 2019

2. Kim SH. Morbid obesity and excessive hospital resource consumption for unilateral primary hip and knee arthroplasty. The Journal of arthroplasty 25(8): 1258, 2010

3. Molloy IB, Martin BI, Moschetti WE, Jevsevar DS. Effects of the Length of Stay on the Cost of Total Knee and Total Hip Arthroplasty from 2002 to 2013. J Bone Joint Surg Am 99(5): 402, 2017

4. Clifton R, Norrish AR, Howell FR. Reducing blood loss after total hip arthroplasty: A prospective randomised controlled trial to evaluate the efficacy of temporarily clamping drains. Hip Int 15(2): 108,2005

5. Carling MS, Jeppsson A, Eriksson BI, Brisby H. Transfusions and blood loss in total hip and knee arthroplasty: a prospective observational study. J Orthop Surg Res 10: 48, 2015

6. Gwam CU, Mistry JB, Mohamed NS, Thomas M, Bigart KC, Mont MA, Delanois RE. Current Epidemiology of Revision Total Hip Arthroplasty in the United States: National Inpatient Sample 2009 to 2013. The Journal of arthroplasty 32(7): 2088, 2017

7. $\mathrm{Ma} \mathrm{QH}$, Fang JH. International normalized ratio for the guidance of warfarin treatment in elderly patients after cardiac valve replacement. Exp Ther Med 17(2): 1486, 2019

8. Ofek F, Barchel D, Perets N, Ziv-Baran T, Mahajna A, Filipovich-Rimon T, Garach-Jehoshua O, Berlin M, Berkovitch M. International Normalized Ratio as a Screening Test for Assessment of Anticoagulant Activity for Patients Treated With Rivaroxaban or Apixaban: A Pilot Study. Front Pharmacol 10: 1177, 2019

9. Glover Williams A, Odd D, Bates S, Russell G, Heep A. Elevated International Normalized Ratio (INR) is Associated With an Increased Risk of Intraventricular Hemorrhage in Extremely Preterm Infants. J Pediatr Hematol Oncol 41(5): 355, 2019

10. Guimaraes PO, Lopes RD, Alexander JH, Thomas L, Hellkamp AS, Hijazi Z, Hylek EM, Gersh BJ, Garcia DA, Verheugt FWA, Hanna M, Flaker G, Vinereanu D, Granger CB. International normalized ratio control and subsequent clinical outcomes in patients with atrial fibrillation using warfarin. J Thromb Thrombolysis 48(1): 27, 2019

11. Rudasill SE, DiPardo B, Sanaiha Y, Mardock AL, Cale M, Antonios JW, Khoury H, Benharash P. International Normalized Ratio (INR) Is Comparable to MELD in Predicting Mortality after 
Cholecystectomy. Am Surg 85(10): 1184, 2019

12. Tan LP, Ye YB, Zhu Y, Gu ZL, Chen QG, Long MY. International normalized ratio on admission predicts the 90-day mortality of critically ill patients undergoing endarterectomy. Exp Ther Med 17(1): 323, 2019

13. Santas E, Minana G, Gummel J, Farcasan R, Paya A, Heredia R, Bodi V, Mollar A, Bertomeu-Gonzalez V, Chorro FJ, Sanchis J, Lupon J, Bayes Genis A, Nunez J. International Normalized Ratio and Mortality Risk in Acute Heart Failure and Nonvalvular Atrial Fibrillation Patients Receiving Vitamin K Antagonists. Rev Esp Cardiol (Engl Ed) 72(8): 616, 2019

14. Acar J, lung B, Boissel JP, Samama MM, Michel PL, Teppe JP, Pony JC, Breton HL, Thomas D, Isnard R, de Gevigney G, Viguier E, Sfihi A, Hanania G, Ghannem M, Mirode A, Nemoz C. AREVA: multicenter randomized comparison of low-dose versus standard-dose anticoagulation in patients with mechanical prosthetic heart valves. Circulation 94(9): 2107, 1996

15. Turpie AG. Safer anticoagulant therapy after heart valve replacement. Recommendations for less intense regimens. Postgraduate medicine 101(3): 85, 1997

16. Leeper CM, Nasr I, McKenna C, Berger RP, Gaines BA. Elevated admission international normalized ratio strongly predicts mortality in victims of abusive head trauma. The journal of trauma and acute care surgery 80(5): 711, 2016

17. Zimmerman RM, Paryavi E, Zimmerman NB, Means KR, Jr. Complications after hand surgery in patients with a raised International Normalized Ratio. The Journal of hand surgery, European volume 42(7): 742, 2017

18. Rudasill SE, Liu J, Kamath AF. Revisiting the International Normalized Ratio (INR) Threshold for Complications in Primary Total Knee Arthroplasty: An Analysis of 21,239 Cases. J Bone Joint Surg Am 101(6): 514, 2019

19. Rudasill SE, Liu J, Kamath AF. Revisiting the International Normalized Ratio Threshold for Bleeding Risk and Mortality in Primary Total Hip Arthroplasty: A National Surgical Quality Improvement Program Analysis of 17,567 Patients. J Bone Joint Surg Am 102(1): 52, 2020

20. Wang D, Wang H-Y, Luo Z-Y, Pei F-X, Zhou Z-K, Zeng W-N. Finding the Optimal Regimen for Oral Tranexamic Acid Administration in Primary Total Hip Arthroplasty: A Randomized Controlled Trial. J Bone Joint Surg Am 101(5): 438, 2019

21. Gibon E, Courpied J-P, Hamadouche M. Total joint replacement and blood loss: what is the best equation? Int Orthop 37(4): 735, 2013

22. Jaramillo S, Montane-Muntane M, Gambus PL, Capitan D, Navarro-Ripoll R, Blasi A. Perioperative blood loss: estimation of blood volume loss or haemoglobin mass loss? Blood Transfus: 1, 2019

23. Knol S, Mallo M, Tromp Meesters R, Westerink J, van de Ree M. The effect of stopping phenprocoumon 5 days preoperatively: A retrospective study. Res Pract Thromb, Haemost 3(24750379 (Electronic)): 85, 2018

24. Roberts HJ, Tsay EL, Grace TR, Vail TP, Ward DT. Increased conditional risk of recurring complications with contralateral total hip arthroplasty surgery. The bone \& joint journal 101- 
b(6_Supple_B): 77, 2019

25. Grace TR, Tsay EL, Roberts HJ, Vail TP, Ward DT. Staged Bilateral Total Knee Arthroplasty: Increased Risk of Recurring Complications. J Bone Joint Surg Am, 2019

26. Xie J, Hu Q, Ma J, Huang Q, Pei F. Multiple boluses of intravenous tranexamic acid to reduce hidden blood loss and the inflammatory response following enhanced-recovery primary total hip arthroplasty: a randomised clinical trial. The bone \& joint journal 99-B(11): 1442, 2017

27. Luo Z-Y, Wang H-Y, Wang D, Zhou K, Pei F-X, Zhou Z-K. Oral vs Intravenous vs Topical Tranexamic Acid in Primary Hip Arthroplasty: A Prospective, Randomized, Double-Blind, Controlled Study. The Journal of arthroplasty 33(3): 786, 2018

28. Yue C, Kang P, Yang P, Xie J, Pei F. Topical application of tranexamic acid in primary total hip arthroplasty: a randomized double-blind controlled trial. The Journal of arthroplasty 29(12): 2452, 2014

29. Yi Z, Bin S, Jing Y, Zongke Z, Pengde K, Fuxing P. Tranexamic Acid Administration in Primary Total Hip Arthroplasty: A Randomized Controlled Trial of Intravenous Combined with Topical Versus Single-Dose Intravenous Administration. J Bone Joint Surg Am 98(12): 983, 2016

30. Partridge T, Jameson S, Baker P, Deehan D, Mason J, Reed MR. Ten-Year Trends in Medical Complications Following 540,623 Primary Total Hip Replacements from a National Database. J Bone Joint Surg Am 100(5): 360, 2018

31. Edmunds I, Avakian Z. Hand surgery on anticoagulated patients: a prospective study of 121 operations. Hand surgery : an international journal devoted to hand and upper limb surgery and related research : journal of the Asia-Pacific Federation of Societies for Surgery of the Hand 15(2): 109,2010

32. Navin PJ, White ML, Nichols FC, Nelson DR, Mullon JJ, McDonald JS, Atwell TD, Moynagh MR. Periprocedural Major Bleeding Risk of Image-Guided Percutaneous Chest Tube Placement in Patients with an Elevated International Normalized Ratio. J Vasc Interv Radiol 30(11): 1765, 2019

33. Arendt CJ, Hong JH, Daly RC, Scott C, Mehta RA, Bailey K, Pathak J, Pereira NL. Time to achieving therapeutic international normalized ratio increases hospital length of stay after heart valve replacement surgery. American heart journal 187: 70, 2017

34. Mirzatolooei F, Tabrizi A, Gargari MM. A Comparison of the Postoperative Complications between Two Drainage Methods after Total Knee Arthroplasty. The archives of bone and joint surgery 6(1): 47, 2018

35. Wu Y, Lu X, Ma Y, Zeng Y, Xiong H, Bao X, Shen B. Efficacy and safety of limb position on blood loss and range of motion after total knee arthroplasty without tourniquet: A randomized clinical trial. International journal of surgery (London, England) 60: 182, 2018

36. Su H, Liu H, Liu J, Wang X. Elderly patients with intertrochanteric fractures after intramedullary fixation : Analysis of risk factors for calf muscular vein thrombosis. Der Orthopade 47(4): 341, 2018

37. Pengas I, Nash W, Reed N, Kumar S. Evidence for treatment of muscular vein thrombosis in orthopaedic patients. Journal of orthopaedics and traumatology : official journal of the Italian 
Society of Orthopaedics and Traumatology 14(3): 159, 2013

38. Yang JH, Yoon JR, Dahuja A, Song S. Subcutaneous versus intraarticular closed suction indwelling drainage after total knee arthroplasty: A randomised control trial. Indian journal of orthopaedics 50(1): 59, 2016

\section{Tables}

TABLE 1. Demographic and comorbidities Characteristics for cases of THA classificated by INR

\begin{tabular}{|c|c|c|c|c|}
\hline Demographics & $\begin{array}{l}\text { Group A } \\
\text { INR } \leq 0.9 \\
(\mathrm{n}=93)\end{array}$ & $\begin{array}{l}\text { Group B } \\
0.9 \square I N R \square 1.0 \\
(n=268)\end{array}$ & $\begin{array}{l}\text { Group C } \\
\text { INR } \geq 1.0 \\
(\mathrm{n}=191)\end{array}$ & $\begin{array}{l}\mathrm{P} \\
\text { Value }\end{array}$ \\
\hline Age* $^{*}($ years $)$ & $55.1 \pm 11.6$ & $54.8 \pm 11.4$ & $56.1 \pm 12.4$ & 0.457 \\
\hline Gender§ & & & & 0.721 \\
\hline Male & $41(44.1 \%)$ & $118(44.0 \%)$ & $91(47.6 \%)$ & \multirow{9}{*}{$\begin{array}{l}0.039 \\
0.976 \\
0.006\end{array}$} \\
\hline Female & $52(55.9 \%)$ & $150(56.0 \%)$ & $100(52.4 \%)$ & \\
\hline Contralateral THA§ & $27(29.0 \%)$ & $45(16.8 \%)$ & $40(20.9 \%)$ & \\
\hline BMI*\# $\left(\mathrm{kg} / \mathrm{m}^{2}\right)$ & $23.4 \pm 2.9$ & $23.4 \pm 3.3$ & $23.4 \pm 3.5$ & \\
\hline ASA class $\S$ & & & & \\
\hline 1 & $18(19.4 \%)$ & $26(9.7 \%)$ & $13(6.8 \%)$ & \\
\hline 2 & $56(60.2 \%)$ & $176(65.7 \%)$ & $109(57.1 \%)$ & \\
\hline 3 & $18(19.4 \%)$ & $62(23.1 \%)$ & $64(33.5 \%)$ & \\
\hline 4 & $1(1.1 \%)$ & $4(1.5 \%)$ & $5(2.6 \%)$ & \\
\hline \multicolumn{5}{|l|}{ Comorbidities } \\
\hline Hypertension§ & $21(22.6 \%)$ & $60(22.4 \%)$ & $47(24.6 \%)$ & 0.847 \\
\hline Diabetes mellitus§ & $4(4.3 \%)$ & $14(5.2 \%)$ & $11(5.8 \%)$ & 0.904 \\
\hline COPD§ & $0(0.0 \%)$ & $5(1.9 \%)$ & $6(3.1 \%)$ & 0.227 \\
\hline Heart disease§ & $2(2.2 \%)$ & $5(1.9 \%)$ & $5(2.6 \%)$ & 0.925 \\
\hline Arrhythmia§ & $3(3.2 \%)$ & $19(7.1 \%)$ & $16(8.4 \%)$ & 0.269 \\
\hline Cancer§ & $2(2.2 \%)$ & $5(1.9 \%)$ & $2(1.0 \%)$ & 0.735 \\
\hline Renal insufficiency§ & $0(0.0 \%)$ & $4(1.5 \%)$ & $3(1.6 \%)$ & 0.685 \\
\hline SLE§ & $3(3.2 \%)$ & $8(3.0 \%)$ & $7(3.7 \%)$ & 0.948 \\
\hline AS§ & $1(1.1 \%)$ & $9(3.4 \%)$ & $7(3.7 \%)$ & 0.541 \\
\hline Venous thrombosis§ & $1(1.1 \%)$ & $5(1.9 \%)$ & $4(2.1 \%)$ & 1.000 \\
\hline Asymptomatic bacteriuria§ & $4(4.3 \%)$ & $22(8.2 \%)$ & $23(12.0 \%)$ & 0.085 \\
\hline Cardiac pacemaker§ & $0(0.0 \%)$ & $0(0.0 \%)$ & $4(2.1 \%)$ & 0.030 \\
\hline \multicolumn{5}{|l|}{ Pre-operative laboratory } \\
\hline Hemoglobin* (g/L) & $136.1 \pm 14.5$ & $133.6 \pm 15.3$ & $131.4 \pm 16.9$ & 0.059 \\
\hline Hematocrit* (L/L) & $0.415 \pm 0.037$ & $0.406 \pm 0.041$ & $0.398 \pm 0.045$ & 0.006 \\
\hline $\mathrm{ESR}^{*}(\mathrm{~mm} / \mathrm{h})$ & $25.16 \pm 18.3$ & $25.0 \pm 16.8$ & $25.6 \pm 20.3$ & 0.942 \\
\hline Platelet count* $\left(\times 10^{9}\right)$ & $185.5 \pm 60.4$ & $184.6 \pm 62.3$ & $178.8 \pm 62.0$ & 0.551 \\
\hline WBC count* $\left(\times 10^{9}\right)$ & $6.1 \pm 1.6$ & $6.2 \pm 2.1$ & $5.8 \pm 1.8$ & 0.076 \\
\hline D-Dimer* (mg/L) & $0.73 \pm 1.0$ & $0.73 \pm 0.9$ & $0.9 \pm 1.0$ & 0.314 \\
\hline Serum albumin* $(\mathrm{g} / \mathrm{L})$ & $44.8 \pm 4.7$ & $43.8 \pm 4.1$ & $42.9 \pm 4.5$ & 0.003 \\
\hline
\end{tabular}

BMI, body mass index; ASA, American Society of Anesthesiologists; COPD, Chronic Obstructive Pulmonary Diseases; SLE, Systemic Lupus Erythematosus; AS, Ankylosing Spondylitis; WBC, White Blood Cell.

*Continuous variables are exhibited as the mean and the standard deviation, analysed by the one-way ANOVA.

$\S$ Categorical variables are exhibited as the number of cases (the percentage), analysed by the Pearson chisquare test or the Fisher exact test.

\#Among the BMI, 11 cases in group B and 2 cases in group C did not acquire BMI data.

TABLE 2. Clinical outcomes for cases of THA classificated by INR 


\begin{tabular}{|c|c|c|c|c|c|c|c|}
\hline Outcomes & $\begin{array}{l}\text { Group A } \\
\text { INR } \leq 0.9 \\
(n=93)\end{array}$ & $\begin{array}{l}\text { Group B } \\
0.9 \square I N R \square 1.0 \\
(n=268)\end{array}$ & $\begin{array}{l}\text { Group C } \\
\text { IN } \geq \geq 1.0 \\
(n=191)\end{array}$ & $\begin{array}{l}\text { P value } \\
\text { A vs. B } \\
\text { vs. C }\end{array}$ & $\begin{array}{l}\mathrm{P} \text { value } \\
\mathrm{A} \text { vs. B }\end{array}$ & $\begin{array}{l}\mathrm{P} \text { value } \\
\mathrm{A} \text { vs. C }\end{array}$ & $\begin{array}{l}\mathrm{P} \text { value } \\
\text { B vs. C }\end{array}$ \\
\hline Transfusion rate§ & $1(1.08 \%)$ & $3(1.12 \%)$ & $11(5.76 \%)$ & 0.008 & 1.000 & 0.112 & 0.004 \\
\hline Blood Loss* (ml) & $895.6 \pm 378.3$ & $915.9 \pm 353.2$ & $978.7 \pm 390.3$ & 0.111 & 0.892 & 0.180 & 0.174 \\
\hline Maximum Hb drop* (g/L) & $25.7 \pm 10.5$ & $26.3 \pm 9.9$ & $27.3 \pm 9.9$ & 0.382 & 0.857 & 0.406 & 0.553 \\
\hline Anemia need medication $\S$ & $15(16.1 \%)$ & $56(20.9 \%)$ & $45(23.6 \%)$ & 0.350 & 0.319 & 0.150 & 0.497 \\
\hline Length of stay* (days) & $4.7 \pm 1.6$ & $5.1 \pm 2.0$ & $5.7 \pm 2.2$ & 0.000 & 0.243 & 0.000 & 0.007 \\
\hline
\end{tabular}

*Continuous variables are exhibited as the mean and the standard deviation, analysed by the one-way ANOVA with post-hoc Tukey test.

$\S$ Categorical variables are exhibited as the number of cases (the percentage), analysed by the Pearson chisquare test or Fisher test.

TABLE 3. Complication and mortality outcomes in 90 days for cases of THA classificated by INR

\begin{tabular}{|c|c|c|c|c|c|c|c|}
\hline Outcomes & $\begin{array}{l}\text { Group A } \\
\text { INR } \leq 0.9 \\
(n=93)\end{array}$ & $\begin{array}{l}\text { Group B } \\
0.9 \square I N R \rrbracket 1 \\
(n=268)\end{array}$ & $\begin{array}{l}\text { Group C } \\
\text { INR } \geq 1 \\
(\mathrm{n}=191)\end{array}$ & $\begin{array}{l}\text { P value } \\
\text { A vs. B vs. C }\end{array}$ & $\begin{array}{l}\text { P value } \\
\text { A vs. B }\end{array}$ & $\begin{array}{l}\text { P value } \\
\text { A vs. C }\end{array}$ & $\begin{array}{l}\mathrm{P} \text { value } \\
\mathrm{B} \text { vs. C }\end{array}$ \\
\hline Any Complication§ & $10(10.8 \%)$ & $44(16.4 \%)$ & $43(22.5 \%)$ & 0.040 & 0.187 & 0.017 & 0.101 \\
\hline Urinary tract infection§ & $0(0.0 \%)$ & $0(0.0 \%)$ & $0(0.0 \%)$ & NA & NA & NA & NA \\
\hline Renal failure§ & $0(0.0 \%)$ & $0(0.0 \%)$ & $0(0.0 \%)$ & NA & NA & NA & NA \\
\hline Stroke§ & $0(0.0 \%)$ & $0(0.0 \%)$ & $0(0.0 \%)$ & NA & NA & NA & $\mathrm{NA}$ \\
\hline Cardiovascular accident§ & $0(0.0 \%)$ & $1(0.4 \%)$ & $4(2.1 \%)$ & 0.157 & 1.000 & 0.307 & 0.166 \\
\hline Pneumonia§ & $0(0.0 \%)$ & $0(0.0 \%)$ & $1(0.5 \%)$ & 0.514 & NA & 1.000 & 0.416 \\
\hline Stroke§ & $0(0.0 \%)$ & $0(0.0 \%)$ & $0(0.0 \%)$ & NA & NA & NA & NA \\
\hline Septic shock§ & $0(0.0 \%)$ & $0(0.0 \%)$ & $0(0.0 \%)$ & NA & NA & NA & $\mathrm{NA}$ \\
\hline Pulmonary embolism§ & $0(0.0 \%)$ & $0(0.0 \%)$ & $0(0.0 \%)$ & NA & NA & NA & NA \\
\hline DVT§ & $1(1.1 \%)$ & $0(0.0 \%)$ & $0(0.0 \%)$ & 0.168 & 0.258 & 0.327 & $\mathrm{NA}$ \\
\hline Superficial infection§ & $0(0.0 \%)$ & $5(1.9 \%)$ & $5(2.6 \%)$ & 0.358 & 0.334 & 0.176 & 0.748 \\
\hline Deep infection§ & $0(0.0 \%)$ & $0(0.0 \%)$ & $0(0.0 \%)$ & NA & NA & NA & NA \\
\hline Dislocation§ & $1(1.1 \%)$ & $1(0.4 \%)$ & $3(1.6 \%)$ & 0.321 & 0.449 & 1.000 & 0.312 \\
\hline Fracture§ & $0(0.0 \%)$ & $0(0.0 \%)$ & $2(1 \%)$ & 0.264 & NA & 1.000 & 0.173 \\
\hline Muscular vein thrombosis§ & $2(2.2 \%)$ & $11(4.1 \%)$ & $10(5.2 \%)$ & 0.473 & 0.528 & 0.348 & 0.568 \\
\hline Subcutaneous ecchymosis§ & $6(6.5 \%)$ & $21(7.8 \%)$ & $17(8.9 \%)$ & 0.769 & 0.662 & 0.478 & 0.683 \\
\hline Hematoma§ & $0(0.0 \%)$ & $3(1.1 \%)$ & $2(1.0 \%)$ & 0.856 & 0.572 & 1.000 & 1.000 \\
\hline Wound-healing delay§ & $1(1.1 \%)$ & $3(1.1 \%)$ & $4(2.1 \%)$ & 0.718 & 1.000 & 1.000 & 0.457 \\
\hline Re-operation§ & $0(0.0 \%)$ & $2(0.7 \%)$ & $4(2.1 \%)$ & 0.272 & 1.000 & 0.307 & 0.239 \\
\hline Mortality in 90 days§ & $0(0.0 \%)$ & $0(0.0 \%)$ & $0(0.0 \%)$ & NA & NA & NA & NA \\
\hline Mortality in 12 months & $0(0.0 \%)$ & $0(0.0 \%)$ & $2(1.0 \%)$ & 0.264 & NA & 1.000 & 0.173 \\
\hline
\end{tabular}

DVT, deep venous thrombosis.

*Continuous variables are exhibited as the mean and the standard deviation, analysed by the one-way ANOVA with post-hoc Tukey test.

$\S$ Categorical variables are exhibited as the number of cases (the percentage), analysed by the Pearson chisquare test or Fisher test. 


\begin{tabular}{lll}
\hline & \multicolumn{2}{c}{ Transfusion rate } \\
\cline { 2 - 3 } Factor & OR $(95 \% \mathrm{CI})$ & P value \\
\hline Unadjusted & & \\
INR class & Reference & - \\
INR $\leq 0.9$ & $1.04(0.11$ to 10.14$)$ & 0.972 \\
$0.9<$ INR $<1$ & $5.62(0.72$ to 44.22$)$ & 0.101 \\
INR $\geq 1$ & & \\
Adjusted* & & \\
INR class & Reference & - \\
INR $\leq 0.9$ & $0.34(0.03$ to 3.90$)$ & 0.384 \\
$0.9<$ INR $<1$ & $1.11(0.11$ to 11.00$)$ & 0.929 \\
INR $\geq 1$ &
\end{tabular}

*Adjusted for contralateral THA, ASA class, asymptomatic bacteriuria, cardiac pacemaker, preoperative hemoglobin, hematocrit, WBC count and serum albumin.

TABLE 5. Outcomes of Binary Logistic Regressions on complication in 90 days

\begin{tabular}{lll}
\hline & \multicolumn{2}{c}{ Complication rate in 90 days } \\
\cline { 2 - 3 } Factor & & OR $(95 \% \mathrm{CI})$ \\
\hline Unadjusted & & \\
INR class & & - \\
$\quad$ INR $\leq 0.9$ & Reference & 0.190 \\
$0.9<\mathrm{INR}<1$ & $1.63(0.79$ to 3.39$)$ & 0.020 \\
INR $\geq 1$ & $2.41(1.15$ to 5.05$)$ & \\
Adjusted & & \\
INR class & & - \\
INR $\leq 0.9$ & Reference & 0.353 \\
$0.9<$ INR $<1$ & $1.43(0.67$ to 3.02$)$ & 0.096 \\
INR $\geq 1$ & $1.93(0.89$ to 4.19$)$ & \\
\hline
\end{tabular}

*Adjusted for contralateral THA, ASA class, asymptomatic bacteriuria, cardiac pacemaker, preoperative hemoglobin, hematocrit, WBC count and serum albumin.

\section{Figures}




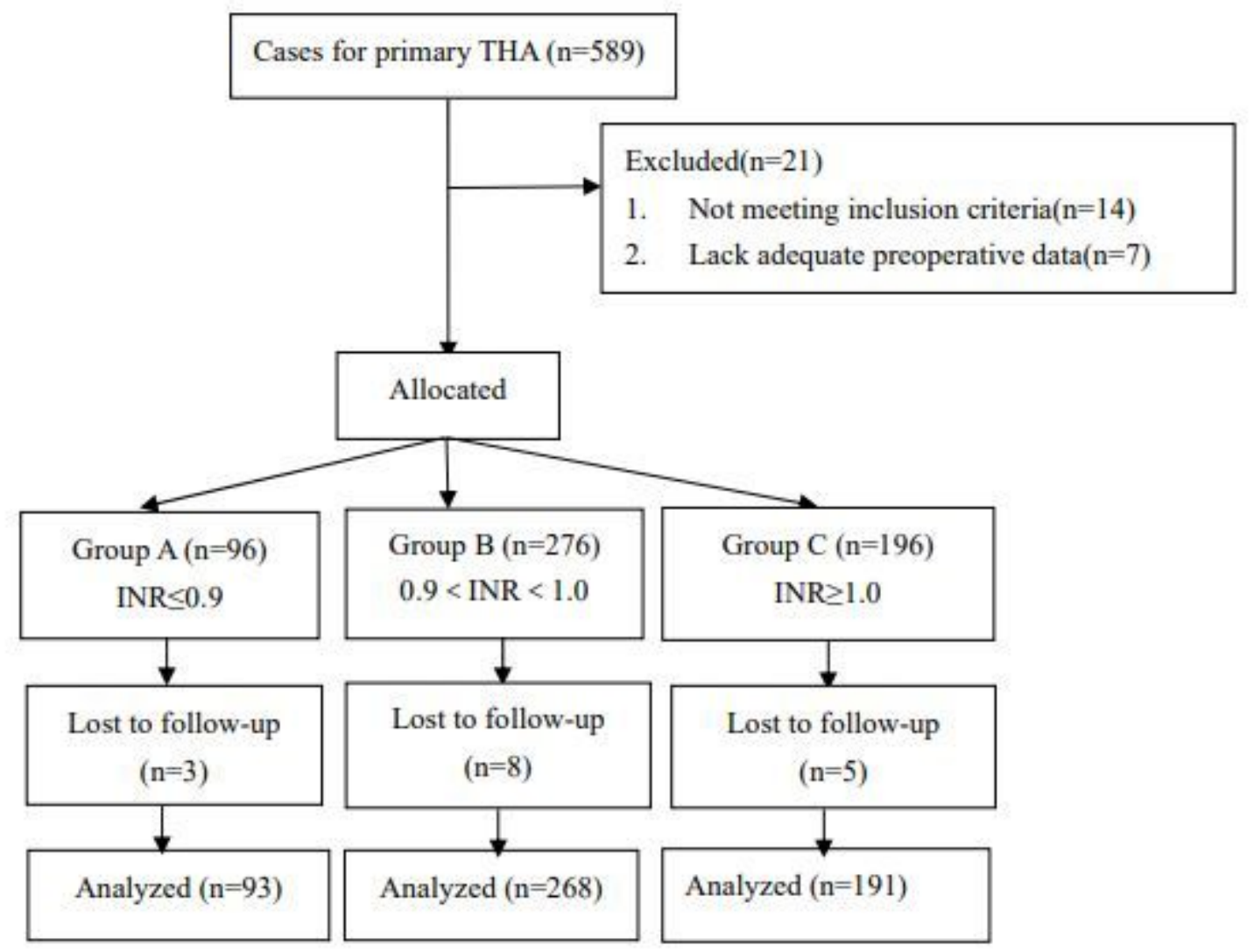

Figure 1

Flow diagram of cases involved 


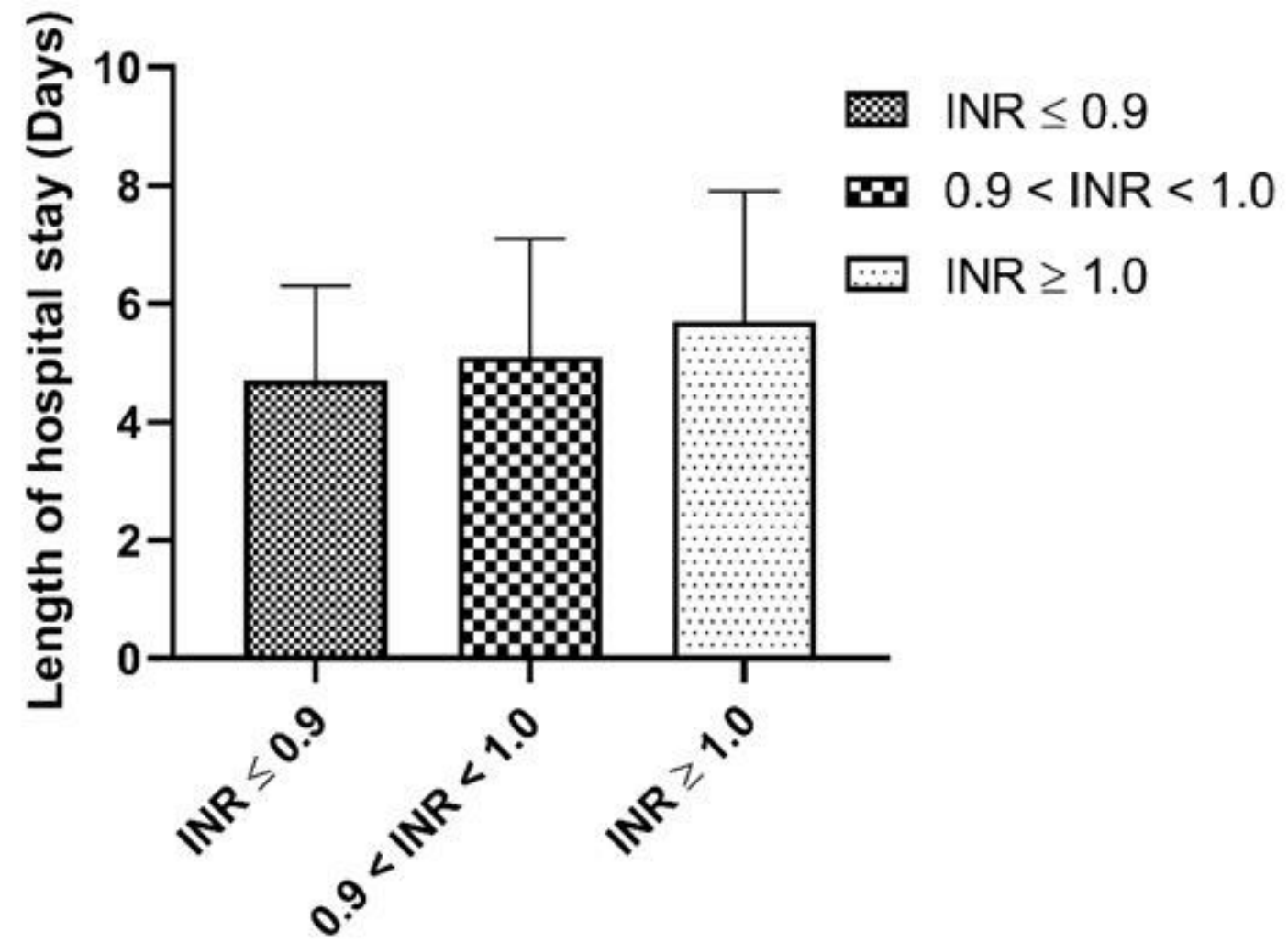

INR Class

Figure 2

Outcomes of the length of stay 